\title{
Income Convergence in the European Union: National and Regional Dimensions
}

\author{
Ana-Maria Holobiuc*
}

\begin{abstract}
:
With advancement of the European integration process, income convergence has become a debated topic that has challenged both the academic forums andthe decision-makers' community. With the first waves of the EU enlargement, it has become indisputable for the European leaders that in order to ensure economic and political stability, the European Union has to promote convergence between countries and regions. The main purpose of this paper is to study income convergence in the European Union by taking into consideration both the national and regional dimensions. In this respect, we have examined (absolute) $\beta$ - and $\sigma$-convergence between 2000 and 2018, finding evidences in favour of the neoclassical growth model assumptions. The results of our study confirm the $\beta$-convergence hypothesis as the poorer countries and regions from Central and Eastern Europe experienced higher growth rates than the developed ones. In the second part of our paper, we have tried to examine the key drivers of economic growth in the European Union (conditional $\beta$-convergence). Our study suggests that variables such as gross fixed capital formation, real labour productivity and labour force participation rate had a positive impact on convergence. In contrast, the growth rates in the European Union were hampered by over-indebtedness, high rates of inflation and unemployment. These internal vulnerabilities together with external challenges threaten the stability and prosperity of the European continent. Consequently, the European Union needs more than ever to reconsider its growth model in order to ensure long-term convergence and to avoid the polarisation between its Members.
\end{abstract}

Key words: European Union; income convergence; NUTS 2 regions;

$\beta$-convergence; $\sigma$-convergence

JEL classification: $\mathrm{O} 40 ; \mathrm{O} 52 ; \mathrm{O} 57$.

\section{Introduction}

One of the biggest challenges for an enlarged European Union (EU) is to ensure economic, social and territorial cohesion among its Members. Although at the beginning of the integration process, the founding Members had similar economic and development levels, the expansion of the regional group has called into question the objective of convergence. In order to overcome the current economic, social and sanitary turmoil, the EU needs more than ever to prove

Ana-Maria Holobiuc; The Bucharest University of Economic Studies, 6 Piata Romana, $1^{\text {st }}$ district, 010374 Bucharest, Romania, <anamaria_holobiuc@yahoo.com>. 
its success in creating the appropriate conditions for long-term convergence between countries and regions. The aim of this paper is to study the economic growth patterns in the EU between 2000 and 2018, by taking into consideration the national and regional dimensions. In this respect, we have compared the results of (absolute) $\beta$ - and $\sigma$-convergence between countries and regions (NUTS 2), finding evidence in favour of the $2 \%$ law of convergence. Moreover, our study confirms the neoclassical growth model assumptions, as the initially poorer Members from Central and Eastern Europe experienced higher growth rates than the developed ones from North-Western Europe. In the second part of our paper, we have tried to examine the key drivers of convergence by taking into consideration economic and social variables. Using panel regressions, we have demonstrated that factors such as gross fixed capital formation (investment), real labour productivity and labour force participation rate had a positive impact on economic growth between 2000 and 2018. In contrast, the excessive debt, high inflation rates and unemployment hampered the economic growth at Community's level.

Although the topic of economic growth has been widely studied, we have tried to conduct an analysis of income convergence between countries and regions, illustrating that the catching-up process is neither automatic nor uniformly distributed. Moreover, we have examined some key drivers of economic growth, concluding that the EU Member States should avoid excessive debt and high inflation and focus on increasing investments and labour productivity. In this respect, our paper emphasise that EU should promote sustainable convergence among its Members, based on fiscal discipline. Moreover, our study confirms the positive influence of an increased rate of labour force participation on economic growth. Consequently, creating employment opportunities should become a strategic objective for the European decision-makers. The paper is structured as follows. The literature review section is divided in two parts, outlining the researchers' perspectives on convergence and the main trends that took place in the EU at national and regional levels. The following section contains a description of the data and methodology and continues with the presentation of the results of the quantitative study. In this respect, the results section is divided in two parts. Firstly, we have presented the results of the comparative analysis of (absolute) $\beta$ - and $\sigma$-convergence at national and regional levels. Then, we have explained the main findings of the conditional convergence model aiming at the economic growth determinants. The concluding section summarises the main findings along with limitations and future directions of research. 


\section{Literature Review}

\subsection{National dimension}

Although at the beginning of the integration process, the founding countries had similar economic performances, the expansion of the regional group has called into question the objective of convergence. With the new challenges that occurred both at regional and global level, maintaining political stability and economic cohesion between its Members has become a strategic objective for the EU. Nowadays, the literature aiming at the topic of the economic growth in the EU is vast and usually covers both the aggregate and sub-group analysis of links between the New and Old Members. Kaitila (2004), Reza and Zahra (2008), Vojinović et al. (2009), Raileanu Szeles and Marinescu (2010), Stanišić (2012), Nenovsky and Tochkov (2013), Dobrinsky and Havlik (2014), Matkowski et al. (2016), Alcidi et al. (2018a), Rapacki and Próchniak (2019), and Stoica et al. (2019) examined income in the EU while also analysing the trends that occurred in Central and Eastern Europe. Kaitila (2004) demonstrated that income gaps between countries diminished at the beginning of the 21st century, while Stanišić (2012) concluded that the New Member States recorded higher growth rates than the Old Member States between 1993 and 2010, although the discrepancies at the Community's level continued to be persistent. Similarly, Alcidi et al. (2018a) found evidences in favour of income convergence in the Central and Eastern Europe countries between 2000 and 2015. In contrast, Alcidi et al. illustrated that the growth rates of the Mediterranean countries were modest, this group lagging behind the rest of the Members.

Dobrinsky and Havlik (2014) found evidence in favour of the absolute and conditional $\beta$-convergence, the convergence speed in the EU being around $2 \%$ per year in both scenarios. The study conducted by Dobrinsky and Havlik suggests that the unit labour cost was the main determinant of convergence between 2000 and 2011. In contrast, Dobrinsky (2013) illustrated that economic growth between 2000 and 2011 was based mainly on over-indebtedness among the Member States. However, Dobrinsky emphasised that the New Member States have generally avoided the fiscal slippage. Rapacki and Próchniak (2019) identified a convergence speed of $2.2 \%$ between 1995 and 2015, the leaders of the convergence process being the Baltic States, which recorded annual growth rates of 4.5-5\%. In the group of Old Members, Luxembourg and Ireland experienced the highest growth rates. In the same line, Stoica et al. (2019) studied absolute convergence between 1995 and 2018, identifying an aggregate convergence speed of $2.63 \%$. Moreover, by studying conditional convergence, Stoica et al. illustrated that investment played a major role in enhancing economic growth in the EU, while the inflation rate, capital flows and private lending had a negative impact. 
Rapacki and Próchniak (2019) investigated the main drivers of convergence, taking into consideration variables related to the EU membership, together with other economic and social factors. The analysts empirically demonstrated that the EU membership has significantly enhanced income convergence in Central and Eastern Europe. At the same time, the process of economic growth was favoured by the strengthening of the institutional quality and increased trade and financial integration. Moreover, Próchniak (2011) demonstrated that FDI and gross fixed capital formation played a major role in catalysing economic growth in Central and Eastern Europe. At the same time, Próchniak highlighted the importance of the human capital in enhancing convergence in the former communist states, illustrating that a higher proportion of employees with tertiary education would positively influence the GDP growth rate. Próchniak also identified a negative relationship between government balance and public debt and economic growth. In terms of the population structure, Próchniak showed that a larger proportion of active population enhances the GDP growth rate. At the same time, Stanišic (2012) illustrated that the convergence process between 1993 and 2010 was positively influenced by an increased level of education, life expectancy at birth, investments, exports and a positive public balance. In contrast, the growth rate was inversely correlated with the fertility rate and inflation. Similarly, Raileanu Szeles and Marinescu (2010) illustrated that labour productivity and trade openness had a positive and strong influence on growth in Central and Eastern Europe.

In conclusion, the vast majority of the studies aiming at the topic of convergence bring evidence in favour of the $2 \%$ law of convergence among the EU Member States. Moreover, recent research confirms the progress achieved by the Central and Eastern European group, where the economic growth rates tend to be higher than the Community's average. However, the study of the key drivers of economic growth remains a challenging topic, its complexity calling for further research.

\subsection{Regional dimension}

The regional dimension of convergence has become a topic of great interest with the deepening and enlargement of the European Economic Community. The objective of reducing disparities between regions was established in the preamble to the Treaty of Rome (1957/1958), with the purpose to strengthen the unity of economies. With the subsequent stages of enlargement of the EU, some voices argued that the accession of the Mediterranean and the Central and Eastern European countries would enhance the disparities between countries and regions. Convergence in the EU by taking into consideration the regional dimension has been studied by Neven and Gouymte (1995), Magrini (1999), Boldrin and Canova (2001), Tondl and Vuksic (2003), Marelli (2007), Ezcurra et 
al. (2006), Geppert and Stephan (2008), Monfort (2008), Petrakos and Artelaris (2009), Artelaris et al. (2010), Goecke and Hüther (2016), Alcidi et al. (2018b).

Alcidi et al. (2018b) compared the economic growth patterns at national and regional levels between 2000 and 2015, finding evidence in favour of the convergence process (both $\beta$ - and $\sigma$-convergence). The winners of the convergence process were the Central and Eastern European countries and regions, but the benefits were not equally distributed. In this respect, when compared to other regions the capital cities have experienced relatively higher growth rates since 2000, mainly in the countries such as Bulgaria, Czech Republic, Poland, Romania and Hungary. In contrast, in the developed countries from NorthWestern Europe, the analysts identified an opposite trend: the capital cities tend to lose their supremacy in favour of other regions. This trend might increase convergence at national levels, avoiding polarisation between capitals and other regions.

In contrast, Magrini (1999) analysed income convergence between 1979 and 1990, concluding that the European regions were diverging from the EU's average. Similarly, Neven and Gouyette (1995) studied regional convergence between 1975 and 1989, illustrating that the growth rates were lower in the EU compared to the United States. Neven and Gouyette identified different trends among the European regions depending on the geographical location (Nord versus South). Boldrin and Canova (2001) did not find evidence in favour of a strong trend of convergence at the regional level. Rather, the results of Boldrin and Canova's study suggest that the growth rates differentials will be maintained in the forthcoming period. The analysts identified the lack of convergence in the field of unemployment, but a slight improvement in terms of productivity.

Marelli (2007) found evidence in favour of regional convergence, taking into consideration the results of $\beta$-convergence. According to the analyst, in the case of the Eurozone countries the catching-up process continued even after the adoption of the single currency. However, Marelli identified an opposite trend in the Central and Eastern European region, namely divergence, mainly in employment. From another perspective, Tondl and Vuksic (2003) studied convergence in Central and Eastern Europe at the end of the last century, taking into consideration 36 NUTS II regions from the Czech Republic, Slovakia, Slovenia, Poland and Hungary. The analysts based their study on the hypothesis that the accumulation of capital, the transfer of technology and the high level of education catalysed the economic growth. The results of the study suggested that FDI had a major contribution in enhancing the economic performances between 1995 and 2000 . 
Considering the complexity of the topic, we have tried to study real convergence by taking into consideration the evolutions that occurred in the EU both at the national and regional levels. Consequently, one of the main assumptions of our research is that the poorer countries and regions from Central and Eastern Europe experienced a higher pace of income convergence than the developed ones. The analysis of absolute $\beta$ - and $\sigma$-convergence will be completed by the study of the economic growth determinants in the EU.

\section{Data and Methodology}

Income convergence is a complex process that can be analysed from multiple perspectives. The instruments and quantitative methods evolved in parallel with the economic growth theories and are mainly based on two key-indicators, which were applied by Barro and Sala-i-Martin (1990, 1992): $\beta$ - and $\sigma$-convergence. Moreover, researchers have developed two categories of $\beta$-convergence, depending on the assumptions of the model. The concept of $\beta$-convergence derives from the neoclassical growth model (Solow, 1956) and is based on the assumption of the diminishing returns to capital. In the neoclassical framework, the initially poorer economies, with a lower stock of physical capital, experienced higher growth rates due to the higher profitability of the production factors. The absolute convergence model assumes that economies have similar initial development levels and structural characteristics, so they will reach the same state of equilibrium. In contrast, if the economies have different initial conditions and endowments, they may reach different levels of equilibrium. In the conditional framework, the differences between countries are controlled by including other explanatory variables in the regression model. From this perspective, the convergence speed will depend on the distance of each economy from its own equilibrium. The study of $\beta$-convergence has been completed by $\sigma$-convergence, which studies whether income differentials diminish over time. According to Barro and Sala-i-Marin (1990, 1992), " $\beta$-convergence is a necessary, but not a sufficient condition for $\sigma$-convergence". Consequently, although poorer countries may experience higher GDP growth rates compared to more developed economies, this may not be sufficient to reduce the income gaps between them.

In order to estimate (absolute) $\beta$-convergence for countries and regions, we have employed cross-sectional simple regressions, where the dependent variables are the average GDP growth rates between 2000 and 2018 and the independent variables the GDP per capita in the initial year (2000). The regressions have been computed with heteroscedasticity robust errors. Moreover, we have tried to establish whether the accession of the Central and Eastern European countries and of the two Mediterranean islands in 2004 influenced income convergence in the EU. In this respect, we have employed the Chow Breakpoint Test 
considering the year 2004 as a break point for convergence. Moreover, we have used the Cusum chart with the purpose to examine if the evolution of income is placed within the 5\% significance level. $\sigma$-convergence has been estimated based on time-series data taking into consideration the time interval 2000-2018. In this respect, we have studied the convergence patterns both at the aggregate and sub-group level, by structuring the countries and regions depending on the geographic location, respectively: North-Western Europe (Austria, Belgium, Denmark, Finland, France, Germany, Ireland, Luxembourg, Netherlands, Sweden, and United Kingdom), Southern Europe (Cyprus, Greece, Italy, Malta, Portugal and Spain) and Central and Eastern Europe (Bulgaria, Czech Republic, Estonia, Hungary, Latvia, Lithuania, Poland, Romania, Slovakia and Slovenia).

In order to study the key determinants of convergence in the EU (conditional $\beta$ convergence) between 2000 and 2018, we have estimated two equations based on panel regressions. We have initially selected five explanatory variables aiming at the level of investment, the soundness of the public finance and the trade openness. Furthermore, the equation was expanded with other factors which aim at the labour market. In both cases, the dependent variable was the difference of logarithms of the GDP per capita. Data included in our research was retrieved from Eurostat and World Bank. In this respect, we have extracted the GDP per capita (in PPS) from Eurostat database for both the countries and regions at the NUTS 2 level. The following explanatory variables included in the conditional convergence model have been extracted from World Bank database: the gross fixed capital formation as a percentage of GDP (GFCF), the volume of trade (sum of exports and imports) as a percentage of GDP (Trade), the labour force participation rate as a percentage of total population ages 15-64 (LFP) and the unemployment rate as a percentage of total labour force (Unemployment). The general government gross debt as a percentage of GDP (Debt), the general government balance (deficit/surplus) (GGB), the harmonised index of consumer prices (annual rate of change) (HICP) and the real labour productivity per person employed (RLP) were extracted from Eurostat database.

We have employed cross-sectional regressions in order to determine $\beta$ convergence for countries and regions, based on the equation presented below:

$$
\frac{1}{T} \ln \left[\frac{y_{i, t}}{y_{i, 0}}\right]=a+\alpha_{1} \ln \left(y_{i, 0}\right)+\varepsilon_{i}
$$

$y_{i, t}=$ GDP per capita of country/region " $i$ " in the last year (2018)

$y_{i, 0}=$ GDP per capita of country/region " $i$ " in the initial year (2000)

$T=$ length of the period 
$\varepsilon_{i}=$ error term

The speed of convergence was computed as follows:

$$
\beta=-\frac{1}{T} \ln \left(1+\alpha_{1} T\right)
$$

The number of years necessary in order to reach the halfway of the transition period towards equilibrium has been determined based on the formula developed by Mankiw et al. (1992) and subsequently applied by Rapacki and Próchniak (2009), and Dobrinsky and Havlik (2014):

$$
t^{*}=\frac{\ln 0.5}{\beta}
$$

$\sigma$-convergence has been calculated taking into consideration the coefficient of variation of the data sets. In order to compute the variance for the sub-groups of countries and regions, we have taken into consideration the distance of each country and region from the mean of the EU. The indicator has been computed based on time-series data as follows:

$$
\sigma_{t}^{2}=\left(\frac{1}{N}\right) \sum_{i=1}^{N}\left[\left(y_{i, t}\right)-u_{t}\right]^{2}
$$

$y_{i, t}=$ GDP per capita of economy "i i" in $\mathrm{t}$

$u_{t}=$ average income in the EU

$$
\sigma_{t}=\sqrt{\sigma_{t}^{2}}, \quad C V=\frac{\sigma_{t}}{\mu_{t}}
$$

In order to study the key drivers of economic growth in the EU, we have employed panel regressions taking into consideration the equation below:

$$
\begin{aligned}
& \ln y_{i, t}-\ln y_{i, t-1}=a+\alpha_{1} \ln \left(y_{i, t-1}\right)+\alpha_{2}(G F C F)+\alpha_{3}(\text { Debt })+ \\
& \alpha_{4}(G G B)+\alpha_{5}(H I P C)+\alpha_{6}(\text { Trade })+\varepsilon_{i, t}
\end{aligned}
$$

We have expanded Eq. 6 with other explanatory variables as follows:

$$
\begin{aligned}
& \text { lny } y_{i, t}-\operatorname{lny}_{i, t-1}=a+\alpha_{1} \ln \left(y_{i, t-1}\right)+\alpha_{2}(\text { GFCF })+\alpha_{3}(\text { Debt })+ \\
& \alpha_{4}(\text { GGB })+\alpha_{5}(H I P C)+\alpha_{6}(\text { Trade })+\alpha_{7}(R L P)+\alpha_{8}(L F P)+ \\
& \alpha_{9}(\text { Unemployment })+\varepsilon_{i, t}
\end{aligned}
$$

Table 1 presents the statistical description of the variables. 
Tab. 1: Descriptive statistics

\begin{tabular}{lllllr}
\hline & Mean & Median & Maximum & Minimum & Std. Dev. \\
\hline GDP per capita & 24522.05 & 23390.00 & 80860.00 & 5630.000 & 11548.90 \\
GFCF & 22.0746 & 21.5803 & 37.2865 & 11.0735 & 4.0198 \\
Debt & 57.3248 & 50.6000 & 181.2000 & 3.8000 & 34.0121 \\
GGB (+/-) & 2.4888 & -2.4000 & 6.9000 & -32.1000 & 3.5973 \\
HICP & 2.5001 & 2.2000 & 22.5000 & 1.7000 & 2.4730 \\
Trade & 117.06 & 100.3508 & 408.3620 & 45.4187 & 65.7313 \\
RLP & 98.5375 & 100.0000 & 142.5000 & 58.4000 & 10.3379 \\
LFP & 70.5592 & 70.7650 & 83.1620 & 57.1810 & 5.3592 \\
Unemployment & 8.9156 & 7.7692 & 27.4662 & 1.8050 & 4.4050 \\
\hline
\end{tabular}

Source: Authorial computation.

The descriptive statistics illustrate different performance of the Member States, as reflected by the minimum and maximum values in the case of selected economic and social variables. For example, the GDP per capita in Bulgaria represented in 2018 only 1/5 of the income of Luxembourg (15,720 PPS versus 80,860 PPS). Referring to investments in fixed assets, the Baltic States predominantly experienced the highest values of GFCF as a percentage of GDP, while Greece the lowest. As far as the health of the public finance is concerned, it seems that many Member States experienced over-indebtedness. For example, countries like Greece, Italy and Portugal recorded after 2010 increased values of debt, which called into question the stability of the EU and particularly of the Eurozone. Moreover, the lack of fiscal discipline in the Euro countries raised concerns about the viability of the nominal convergence criteria and finally triggered the reform process of the European economic governance. Moreover, not all the Member States had price stability. For example, Romania experienced at the beginning of the 2000s significant values of HICP, reaching even $45.7 \%$ in 2000. The analysis of the evolution of the real labour productivity, considered as one of the main drivers of economic growth, leads us to insightful results. The countries that at the beginning of the period under review experienced modest values, mainly Romania and the Baltic States, were placed in the top of the ranking in 2018. Another success story was that of Ireland, which was the leader in terms of labour productivity in 2018, although in 2000 it was placed close to the bottom of the ranking. Based on our preliminary analysis, we expect that factors such as GFCF, government gross balance, level of debt, volume of trade and real labour productivity exercise a positive influence on economic growth, while HICP and unemployment rates represent a negative impact. 
Holobiuc, A.: Income convergence in the European Union: national and regional dimensions.

\section{Results and Discussion}

\subsection{Convergence in the EU: national versus regional dimension}

Figure 1 illustrates the results of absolute $\beta$-convergence for the EU Member States over the period 2000-2018. The negative slope of the trend line confirms the neoclassical growth model assumptions, suggesting that the countries with lower GDP per capita in 2000 recorded higher growth rates than the developed ones. The highest growth rates were experienced by Romania and the Baltic States exceeding 5\% per year. The countries included in the North-Western group experienced average GDP per capita growth rates, ranging between $4.2 \%$ (Ireland) and $1.8 \%$ (France). In the Southern cluster, Malta recorded the highest convergence speed, reaching 3.4\%, while Greece recorded the lowest figure $(-1 \%)$. Figure 1 suggests polarisation between the New and the Old Members. The Central and Eastern European countries tend to be placed in the upper part of the figure, while the majority of the Old Members are grouped at the bottom. Our results are in line with the previous studies which confirmed that the poorer Central and Eastern European countries experienced higher GDP growth rates than the more developed Old Members (Kaitila, 2004; Rapacki and Próchniak, 2009; Vojinović et al., 2009; Matkowski et al., 2016; Rapacki and Próchniak, 2019).

Fig. 1: $\beta$-convergence in the Member States of the EU between 2000 and 2018

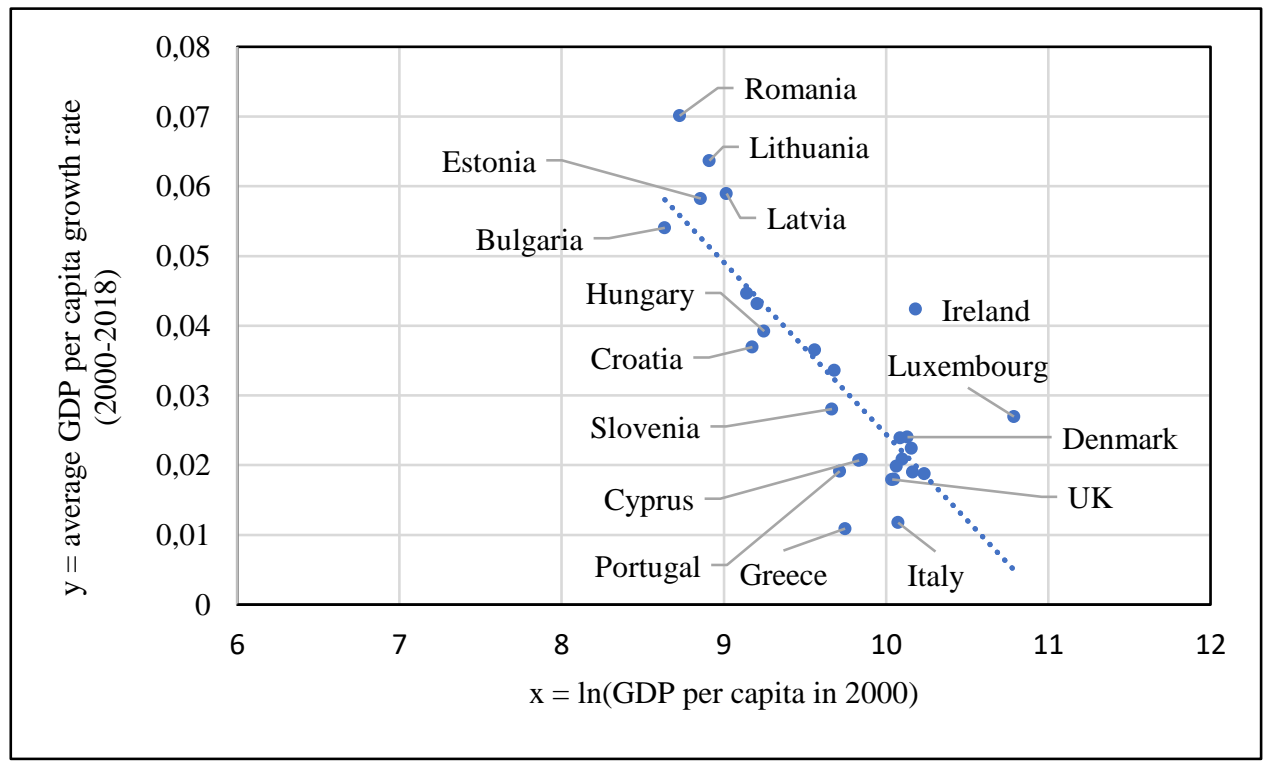

Source: Author's computation.

Note: $\mathrm{y}=-0.0247 \mathrm{x}+0.2711, \mathrm{R}^{2}=0.6672$. 
Figure 2 illustrates the results of $\beta$-convergence among 241 NUTS 2 regions included in the study ${ }^{1}$. According to our calculations, the highest growth rates were recorded by the Central and Eastern European regions between 2000 and 2018. Particularly, Bucuresti-Ilfov region from Romania experienced the highest speed of convergence in the EU, reaching on average $7.5 \%$. Other regions that registered important economic growth rates were Sostinès regionas $(6.6 \%)$ from Lithuania and Yugozapaden (6.4\%) from Bulgaria. In Central and Eastern Europe, the most significant performances were mainly experienced by the wealthy capital regions (Bucuresti-Ilfov in Romania, Sostinès regionas in Lithuania, Yugozapaden in Bulgaria, Bratislavský kraj in Slovakia). This trend calls into question the neoclassical growth model hypothesis that assumes that the less developed economies will experience higher GDP growth rates than the developed ones. In contrast, the majority of the North-Western and Southern NUTS 2 regions recorded average economic growth rates, ranging from 4\% (Eastern and Midland Ireland) to $1 \%$ (Outer London - East, and North East - United Kingdom). In contrast with the positive development which occurred in the Central and Eastern European group, the Southern regions experienced modest performances with the lowest GDP growth rates recorded by the Greek regions. Overall, we have found evidence in favour of the $\beta$-convergence hypothesis, as the less developed regions from Central and Eastern Europe recorded higher GDP growth rates than the developed ones from North-Western Europe. However, as earlier shown by Tondl and Vuksic (2003) and Alcidi (2018b), the main winners of the catching-up process in Central and Eastern Europe tend to be the capitals that continue to improve their relative position to the detriment of the other regions, creating internal divergences.

\footnotetext{
${ }^{1}$ We excluded the NUTS 2 regions from France and Poland due to lack of data for the entire period.
} 
Holobiuc, A.: Income convergence in the European Union: national and regional dimensions.

\section{Fig. 2: $\beta$-convergence in the regions at NUTS 2 level between 2000 and 2018}

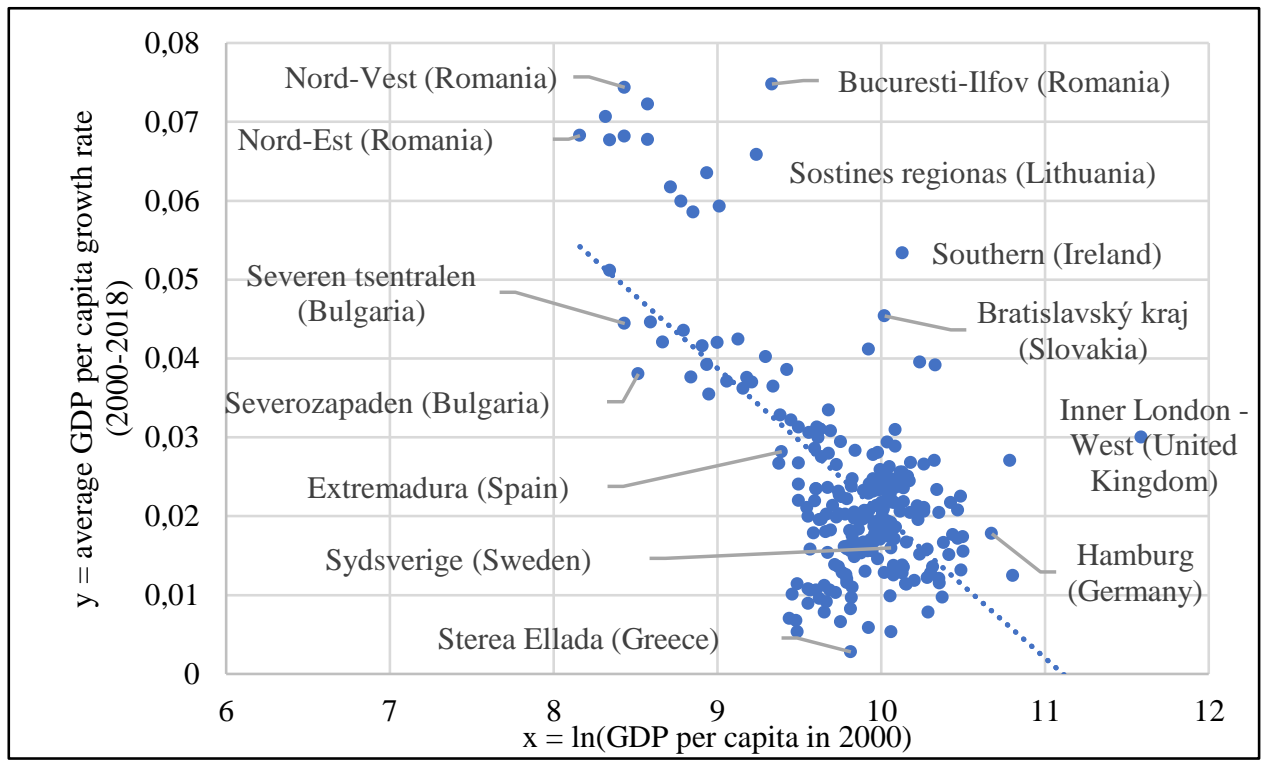

Source: Author's computation.

Note: $\mathrm{y}=-0.0184 \mathrm{x}+0.204, \mathrm{R}^{2}=0.4228$.

Table 2 presents the regression results of absolute $\beta$-convergence for countries and regions. The negative sign of $\alpha$ coefficient confirms the hypotheses of our study, respectively that the poorer economies experienced higher GDP growth rates compared to the developed ones. The value of the R-squared illustrates a strong relationship between the initial level of income and the subsequent growth rates, mainly among countries. The convergence speed computed based on Eq. 2 brings evidence in favour of the $2 \%$ law of convergence (Barro and Sala-i-Martin, 1992). However, the convergence speed among countries is slightly higher than between regions $(2.5 \%$ versus $1.8 \%)$. Taking into consideration the values of $\beta$ convergence, the countries need almost 28 years in order to reach the halfway towards the equilibrium state, while the regions at NUTS 2 level require 37.5 years. These time intervals were determined based on Eq. 3. Lastly, we have illustrated that in spite of the initial concerns that accompanied the process of enlargement, the results of the Chow Breakpoint Test suggest that the year 2004 did not represent a break point for convergence neither at the national nor at the regional level (the F-statistic is not significant, so we accept the null hypothesis of no break). Moreover, the Cusum chart indicates that the evolution of income is placed within the 5\% significance level, no sharp change being identified in 2004. Consequently, the accession of the New Members did not 
hamper the convergence process among countries and regions. In contrast, our analysis suggest that the Central and Eastern European region experienced important progress in terms of catching-up, while the Old Members, mainly the Southern group, find it more and more difficult to maintain their economic growth.

\section{Tab. 2: Regression results for absolute $\beta$-convergence}

\begin{tabular}{crr}
\hline Variable/Included observations & EU (28 countries) & EU (241 regions) \\
\hline$a$ & $0.2711^{*} ;(8.1837)$ & $0.2040^{*} ;(14.9889)$ \\
LOG(GDP PER CAPITA IN 1995) & $-0.0246^{*} ;(-7.2196)$ & $-0.0183^{*} ;(-13.2307)$ \\
R-squared & 0.6671 & 0.4227 \\
Adjusted R-squared & 0.6543 & 0.4203 \\
$\beta$ (convergence speed) & -0.0249 & -0.0184 \\
t* $^{*}$ & 27.8 & 37.5 \\
\hline Chow Breakpoint Test (year 2004) & & 0.6721 \\
Prob. F & 0.8590 & 0.6000 \\
Prob. Chi-Square(2) & 0.8225 & 0.6645 \\
Prob. Chi-Square(2) & 0.8576 &
\end{tabular}

Source: Author's computation.

Note: Dependent Variable: Average GDP per capita growth rate between 2000 and 2018, Method: Least Squares, ${ }^{*}$ - p-value $<1 \%$, T-statistics are shown in parentheses.

The analysis of absolute $\beta$-convergence at national and regional levels has been completed by $\sigma$-convergence. In order to study whether the dispersion of income between countries diminished between 2000 and 2018, we have structured the Member States into three clusters, based on the geographic location: NorthWestern, Southern, and Central and Eastern Europe. Our calculations suggest that at the aggregate level, the income gaps between countries decreased between 2000 and 2018 by $16 \%$. However, there still exist significant gaps between countries. The income differentials among the North-Western group remain high, as reflected by the values of the coefficient of variation. As far as the Southern countries are concerned, the gaps between them increased by 30\%, mainly following the year 2010 as a result of the economic and financial and sovereign debt crises that negatively influenced this group. However, the Southern countries form the most homogenous group, as reflected by the values of the coefficient of variation. The Central and Eastern Europe not only experienced the highest GDP growth rates, but also succeeded to reduce the income differentials between them by $40 \%$. Consequently, $\beta$-convergence was accompanied by $\sigma$-convergence in this group of countries. Moreover, the evolution of the coefficient of variation suggests that the process of convergence occurred before the accession to the new EU Member 
States, being most probably catalysed by the efforts to meet the Copenhagen criteria.

\section{Fig 3: $\sigma$-convergence in the Member States of the EU between 2000 and 2018}

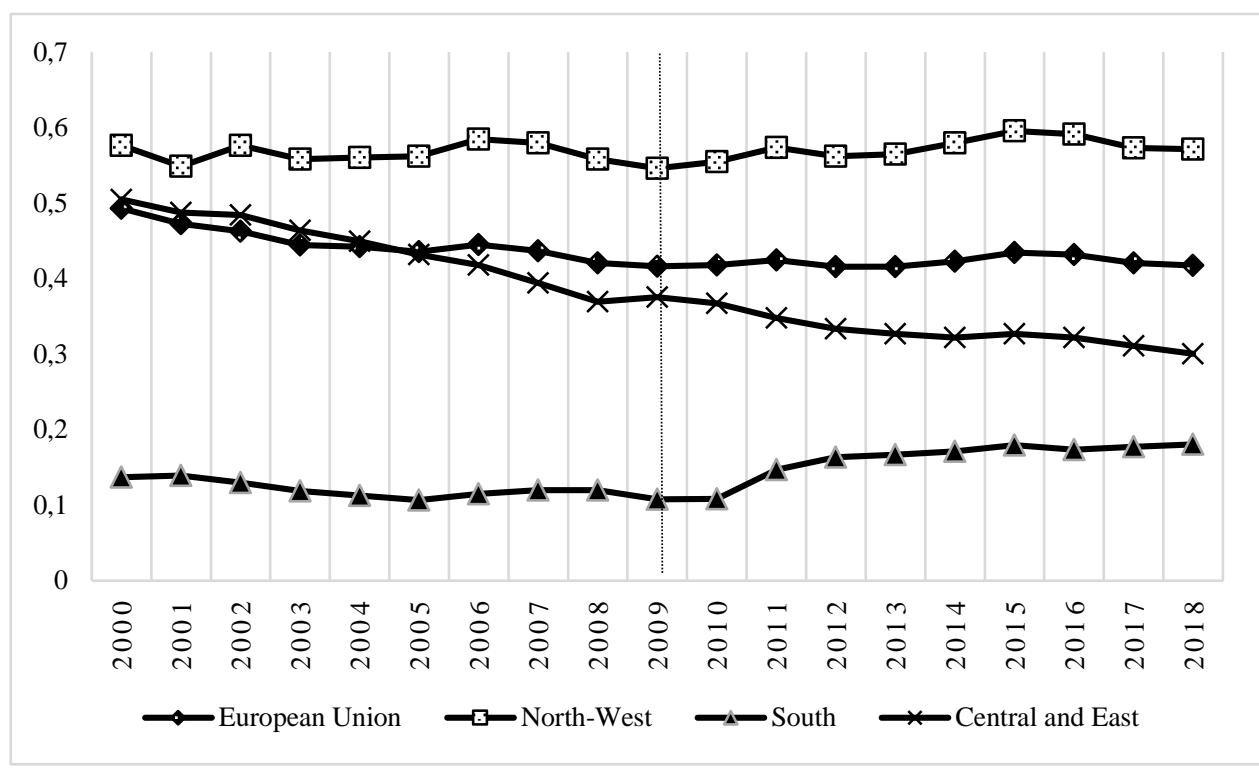

Source: Author's computation.

The analysis of the convergence patterns at national level is completed by the study of $\sigma$-convergence among the NUTS 2 regions. In this respect, Figure 4 illustrates that the income gaps between regions remain significant at the aggregate level. Moreover, it seems that the negative consequences of the economic and financial crisis eroded the progresses achieved until 2008. The income gaps among North-Western regions are particularly high and had an upward trend after 2008. Similarly, the income gaps increased after 2009 in the Southern European regions, but the heterogeneity among the component countries remain at a low level. The Central and Eastern European group experienced a decrease of income disparities by almost 40\%. However, the divergences between regions tend to be higher than between countries, which can be determined by the improvement of the relative position of the capital regions to the detriment of the other geographic zones. Overall, our analysis suggests that also at the regional level, $\beta$-convergence was accompanied by $\sigma$ convergence in the Central and Eastern European cluster. 
Fig. 4: $\sigma$-convergence in the regions at NUTS 2 level between 2000 and 2018

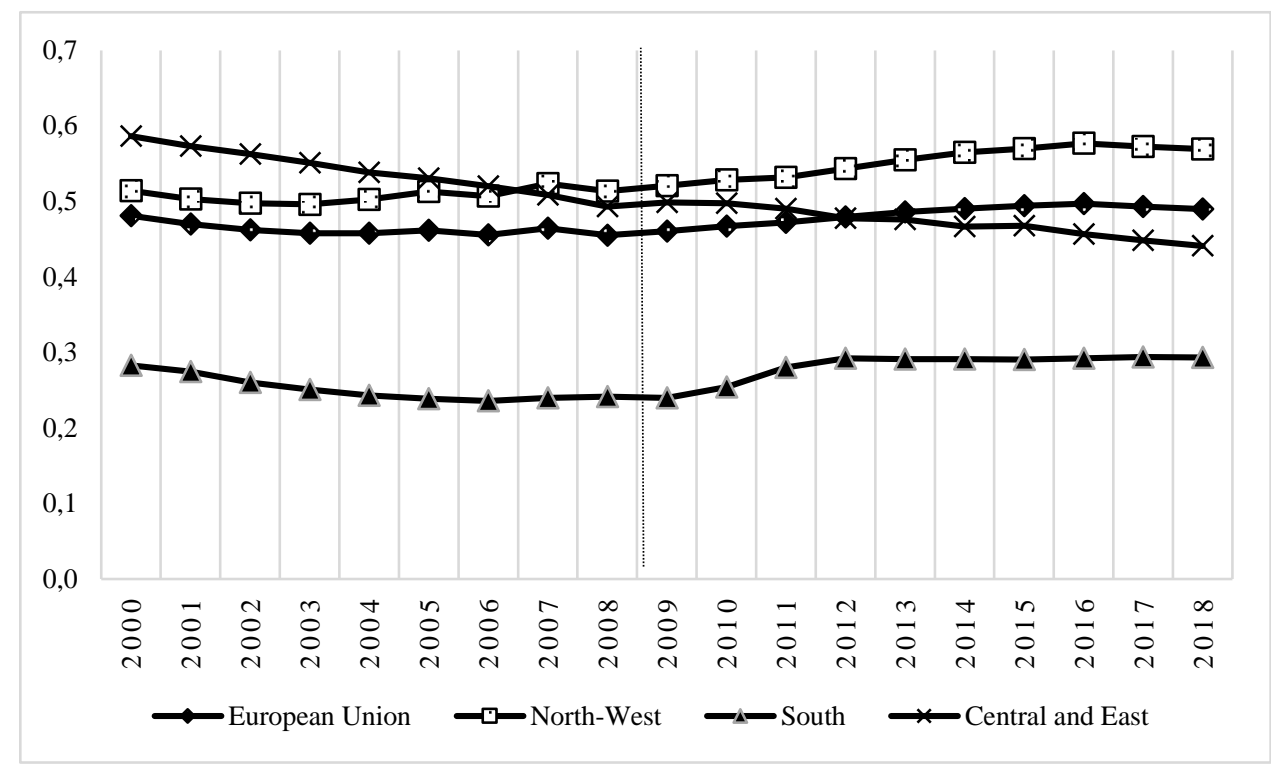

Source: Author's computation.

\subsection{Looking for the key drivers of economic growth in the EU}

As shown above, convergence is neither automatic nor uniform process. In order to explain the main drivers of economic growth in the EU, we have employed panel regression, by including both economic and explanatory variables. We have used the generalised method of moments (GMM) technique in difference (Arellano and Bond, 1991) which has the advantage to deal with the correlation between the explanatory variables and the error terms (endogeneity) (Dobrinsky and Havlik, 2014) and to avoid data redundancy (Rapacki and Próchniak, 2019). First of all, we have studied the influence of six economic variables (including the lagged GDP per capita), as presented in Eq. 6, then expanding the model with other three determinants, as reflected in Eq. 7. We have included the lagged value of the GDP per capita, considered to be an important explanatory variable. As noted by Rapacki and Próchniak (2019), after the identification of absolute convergence, the absence of this variable would bias the estimation. Table 3 presents the results of the conditional convergence model, computed based on Eq. 6. The panel regressions provide some interesting insights aiming at the growth determinants in the EU. First of all, the negative sign of the lagged GDP per capita confirm the neoclassical growth model assumptions, respectively that the poorer Members experienced higher GDP growth rates than the developed ones. As also illustrated by Stoica et al. (2019), the value of the coefficient is higher when 
considering other control variables in the model, but the negative sign is maintained.

The first model illustrates the favourable influence of the investment in fixed assets, as reflected by the positive and significant value of the GFCF and of the trade openness. Our results are in line with the findings of Rapacki and Próchniak (2009) who previously confirmed that these factors have a beneficial influence on economic growth. However, it seems that the value of general government debt and of the HICP had a negative impact on the economic growth rates in the EU. The negative influence of the HICP was also confirmed by the previous studies (Rapacki and Próchniak, 2009; Próchniak, 2011; Stoica et al., 2019). However, the researchers' perspectives referring to the effects of overindebtedness are not homogenous. For example, Dobrinsky and Havlick, (2014) and Stoica et al. (2019) illustrated that the economic growth in the EU was mainly based on over-indebtedness, while Próchniak (2011) identified a negative relationship between excessive debt and convergence. Raileanu Szeles and Marinescu (2010) and Checherita and Rother (2010) concluded that the impact of government debt depends on its size, so large levels might hamper economic growth. Lastly, the general government balance was not significant in the two models, which might suggest the "volatility of the variable" (Dobrinsky and Havlick, 2014). As far as the second model is concerned, the results of our study confirm the strong influence of the real labour productivity on convergence, aspreviously showed by Raileanu Szeles and Marinescu (2010). Particularly, this seems to be the main determinant of economic growth in our model, suggesting that the economic growth in the EU and particularly the progress achieved by the Central and Eastern European group was based mainly on enhancing the labour productivity. Moreover, as expected, the labour force participation rate had a positive impact on economic growth. The significant influence of the labour force participation provides some interesting insights, suggesting that the decisionmakers should create employment opportunities in order to enhance convergence. Our model also confirms the negative influence of high unemployment rates on economic growth. Lastly, we have studied autocorrelation using the Arellano and Bond tests for first and second-order autocorrelation for the regressions equations. The results confirm that there is no second-order autocorrelation for the two models presented below. 
Tab. 3: Regression results for conditional $\beta$-convergence

\begin{tabular}{lrr}
\hline Variables & Model 1; (equation 6) & \multicolumn{1}{c}{ Model 2; (equation 7) } \\
\hline Lagged GDP per capita in 2000 & $-0.5045^{*} ;(-23.0391)$ & $-0.8258^{*} ;(-37.0117)$ \\
GFCF & $0.0545^{* *} ;(2.2626)$ & $0.0510^{*} ;(3.1992)$ \\
Debt & $-0.1099^{*} ;(-7.5168)$ & $-0.0151^{* * *} ;(-1.5510)$ \\
GGB & $0.0006 ;(0.8278)$ & $0.0006 ;(1.2912)$ \\
HICP & $-0.0025^{*} ;(-2.3273)$ & $-0.0003 ;(-0.5117)$ \\
Trade & $0.3818^{*} ;(14.4033)$ & $0.0891 * ;(4.4959)$ \\
RLP & & $1.1621^{*} ;(26.9671)$ \\
LFP & & $0.7312^{*} ;(7.8501)$ \\
Unemployment & & $-0.0519^{*} ;(-6.7114)$ \\
\hline Arellano-Bond Serial Correlation Test & & \\
AR(1) & 0.0100 & 0.8292 \\
AR(2) & 0.9180 & 0.3529 \\
\hline
\end{tabular}

Source: Author's computation

Note: Dependent Variable: GDP per capita growth rate between 2000 and 2018; Method: Panel Generalised Method of Moments; Transformation: First - differences; Total panel observations: 457 $*$ - p-value $<1 \%$; ** - p-value $<5 \%$; *** - p-value $<10 \%$. T-statistics are shown in parentheses.

\section{Conclusion}

The main purpose of this paper was to study income convergence in the EU, trying to conduct a comparative analysis between the evolutions that took place at the national and regional level. In this respect, we have studied absolute $\beta$ - and $\sigma$-convergence, illustrating that the poorer Central and Eastern European countries and regions experienced higher GDP growth rates than the developed NorthWestern European group. Moreover, we have found evidences in favour of the $2 \%$ law of convergence, identifying a convergence speed of $2.5 \%$ among countries and $1.8 \%$ for the NUTS 2 regions. However, the improvement of the relative position of the wealthy capital regions to the detriment of the other regions in Central and Eastern Europe calls into question the neoclassical growth model assumptions and threatens the objective of convergence within countries. In the second part of our paper, we have tried to contribute to the literature by examining the key determinants of economic growth using the conditional $\beta$-convergence. In this respect, we have illustrated that the gross fixed capital formation, together with trade openness, real labour productivity and labour force participation had a positive influence on economic growth. In contrast, high levels 
of government debt, inflation and unemployment hampered the economic growth in the EU between 2000 and 2018. These findings provide some implications for policy-makers. The Member States should increase the investments and continue the process of trade liberalisation in order to catalyse the converge process. Moreover, the real labour productivity proved to be in our model the most important key driver of economic growth. Consequently, the decision-makers should adopt measures that increase the quality of the physical capital and improve the level of education and skills of the labour force.

The labour force participation also proved to be a statistically significant explanatory variable in our model. As expected, this factor had a positive influence on economic growth, which suggests that the European decision-makers should focus on increasing the participation by creating employment opportunities. Moreover, the decision-makers should establish a balanced level of social benefits that protects the disadvantaged groups, but does not discourage the employment of the working-age population. Our study also emphasises the need to assure a sustainable level of convergence by maintaining the soundness of the public finance in the EU. In this respect, we have identified a negative relationship between over-indebtedness and high levels of inflation and convergence. The negative consequences of the excessive government debt can be mainly seen in the Southern European group that find increasingly difficult to maintain economic growth both at national and regional levels. Consequently, the EU needs to reconsider its growth model in order to assure long-term convergence for its Members. Although our study tries to bring some useful insights of convergence patterns at national and regional levels and to present some key drivers of economic growth, one of the main shortcomings is determined by the limited number of variables. In this respect, the conditional model could be expanded in order to include other explanatory variables, related to demography, economic structure and financial sector. Moreover, the analysis of conditional $\beta$-convergence model at regional level would provide further insights of the economic growth drivers in the EU.

\section{References}

Alcidi, C. Ferrer, J. N. Musmeci, R., Di Salvo, M., Pilati, M., 2018 b. Income Convergence in the EU: Within-country regional patterns. Centre for European Policy Studies (CEPS). Available from: <ceps.eu/ceps-publications/incomeconvergence-eu-within-country-regional-patterns/>. [15 September 2020].

Alcidi, C., Ferrer, J. N., Di Salvo, M., Musmeci, R., Pilati, M., 2018 a. Income convergence in the EU: a tale of two speeds. Centre for European Policy Studies (CEPS). Available from: <ceps.eu/ceps-publications/income-convergence-eu-taletwo-speeds/>. [15 September 2020]. 
Arellano, M., Bond, S., 1991. Some Tests of Specification for Panel Data: Monte Carlo Evidence and an Application to Employment Equations. Review of Economic Studies, 58(2), 277-297.

Artelaris, P., Kallioras, D. Petrakos, G., 2010. Regional Inequalities and Convergence Clubs in the European Union New Member-States. Eastern Journal of European Studies, 1(1), 113-133.

Barro, R. J., Sala-i-Martin, X., 1990. Economic Growth and Convergence across the United States. NBER Working Paper 3419,. National Bureau of Economic Research.

Barro, R. J., Sala-i-Martin, X., 1992. Convergence. Journal of Political Economy, 100(2), 223-251.

Boldrin, M., Canova, F., 2001. Inequality and convergence in Europe's regions: reconsidering European regional policies. Centre for Economic Policy Research. Available from: <apps.eui.eu/Personal/Canova/Articles/icoeu.pdf>. [15 September 2020].

Checherita-Westphal, C. D., Rother, P., 2010. The Impact of High and Growing Government Debt on Economic Growth: An Empirical Investigation for the Euro Area. ECB Working Paper No. 1237. European Central Bank. Available from: <ecb.europa.eu/pub/pdf/scpwps/ecbwp1450.pdf>. [15 September 2020].

Dobrinsky, R., 2013. What is happening to Growth in Europe? Research Report No. 385. The Vienna Institute for International Economic Studies. Available from: <wiiw.ac.at/what-is-happening-to-growth-in-europe-p-2894.html>. [15 September 2020].

Dobrinsky, R., Havlik, P., 2014. Economic Convergence and Structural Change: the Role of Transition and EU Accession. Research Report No. 395. The Vienna Institute for International Economic Studies. Available from: $<$ wiiw.ac.at/economic-convergence-and-structural-change-the-role-of-transitionand-eu-accession-p-3357.html>. [15 September 2020].

Eurostat, 2020. Database Available from: <ec.europa.eu/eurostat/data/database>

Ezcurra, R., Pascual, P., Rapún, M., 2006. Regional Specialization in the European Union. Regional Studies, 40(6), 601-616.

Geppert, K., Stephan, A., 2008. Regional disparities in the European Union: Convergence and agglomeration. Regional Science, 87(2), 193-217.

Goecke, H., Hüther M., 2016. Regional Convergence in Europe. Intereconomics: Review of European Economic Policy, 51(3), 165-171. 
Holobiuc, A. M., 2020. Challenges for Regional Convergence in the European Union. Annals of the "Constantin Brâncuşi”, Economy Series, 3/2020, 131-136.

Kaitila, V. 2004. Convergence of real GDP per capita in the EU15. How do the Accession Countries fit in? European Network of Economic Policy Research Institutes 25. Available from: <aei.pitt.edu/1843/1/ENEPRI_WP25.pdf>. [15 September 2020].

Magrini, S. 1999. The evolution of income disparities among the regions of the European Union. Regional Science and Urban Economics, 29(2), 257-281.

Mankiw, G., N., Romer D. and Weil, D. N., 1992. A Contribution to the Empirics of Economic Growth. The Quarterly Journal of Economics, 107(2), 407-437.

Marelli, E., 2007. Specialisation and Convergence in European Regions. European Journal of Comparative Economics, 4(2), 149-178.

Matkowski, Z., Próchniak, M. and Rapacki, R., 2016. Real Income Convergence between Central Eastern and Western Europe: Past, Present, and Prospects. 33rd Centre for International Research on Economic Tendency Surveys Conference on Economic Tendency Surveys and Economic Policy (September 14 - September 17, 2016). Available from: <econstor.eu/handle/10419/146992>. [15 September 2020].

Monfort, P., 2008. Convergence of EU regions. Measures and evolution. Working paper 1. European Commission, Directorate-General for Regional Policy. Available from: <ec.europa.eu/regionalpolicy/sources/docgener/work /200801 convergence.pdf>. [15 September 2020].

Nenovsky, N., Tochkov, K., 2013. The Distribution Dynamics of Income in Central and Eastern Europe relative to the EU: A Nonparametric Analysis. William Davidson Institute Working Paper, 1063.

Neven, D., Gouymte C., 1995. Regional Convergence in the European Community. Journal of Common Market Studies, 33(1), 47-65.

Petrakos G., Artelaris P., 2009. European Regional Convergence Revisited: A Weighted Least Squares Approach. Growth and Change, Wiley Blackwell 40(2), 314-331.

Petrakos, G., Rodríguez-Pose, A., Rovolis, A., 2005. Growth, Integration, and Regional Disparities in the European Union. Environment and Planning A: Economy and Space, 37(10), 1837-1855.

Próchniak, M., 2011. Determinants of economic growth in Central and Eastern Europe: the global crisis perspective. Post-Communist Economies, 23(4), 449468. 
Raileanu Szeles, M., Marinescu, N., 2010. Real convergence in the CEECs, Euro Area accession and the Role of Romania. European. Journal of Comparative Economics, 7(1), 181-202.

Rapacki, R., Próchniak, M, 2019. EU membership and economic growth: empirical evidence for the CEE countries. European Journal of Comparative Economics, 16(1), 3-40.

Rapacki, R., Próchniak, M., 2009. Real Beta and Sigma Convergence in 27 Transition Countries, 1990-2005. Post-Communist Economies, 21(3), 307-326.

Reza, R., Zahra K. T., 2008. Evaluation of the Income Convergence Hypothesis in Ten New Members of the European Union. A Panel Unit Root Approach. Panoeconomicus, 55(2), 157-166. DOI: 10.2298/PAN0802157R.

Solow, R. M., 1956. A Contribution to the Theory of Economic Growth. The Quarterly Journal of Economics, 70(1), 65-94.

Stanišić, N., 2012. The effects of the economic crisis on income convergence in the European Union. Acta Oeconomica, 62(2), 161-182.

Stoica, O., Roman, A., Diaconaşu, D. E., 2019. Real Convergence and European Integration with Focus on the New Member States. Scientific Annals of Economics and Business, 66(SI2), 215-228.

Tondl, G., Vuksic, G., 2003. What makes regions in Eastern Europe catching up? The role of foreign investment, human resources and geography. ZEI Working Paper, No. B 12-2003. ZEI - Center for European Integration Studies, University of Bonn. Available from: <epub.wu.ac.at/274/1/document.pdf>. [15 September 2020].

Vojinović, B., Acharya, S., Próchniak, M., 2009. Convergence Analysis among the Ten European Transition Economies. Hitotsubashi Journal of Economics, 50(2), 17-35.

World Bank, 2020. Data. Available from: <data.worldbank.org/>. [15 September 2020]. 